University of Nebraska - Lincoln

DigitalCommons@University of Nebraska - Lincoln

USDA National Wildlife Research Center - Staff Publications
U.S. Department of Agriculture: Animal and Plant Health Inspection Service

2013

\title{
Pheromonal control of the invasive brown treesnake: potency of female sexual attractiveness pheromone varies with ovarian state
}

Tom Mathies

US Department of Agriculture, tomcmathies@gmail.com

Breanna Levine

US Department of Agriculture

Richard M. Engeman

USDA-APHIS-Wildlife Services, s_r100@yahoo.com

Julie A. Savidge

Colorado State University, julie.savidge@colostate.edu

Follow this and additional works at: https://digitalcommons.unl.edu/icwdm_usdanwrc

Part of the Life Sciences Commons

Mathies, Tom; Levine, Breanna; Engeman, Richard M.; and Savidge, Julie A., "Pheromonal control of the invasive brown treesnake: potency of female sexual attractiveness pheromone varies with ovarian state" (2013). USDA National Wildlife Research Center - Staff Publications. 1521.

https://digitalcommons.unl.edu/icwdm_usdanwrc/1521

This Article is brought to you for free and open access by the U.S. Department of Agriculture: Animal and Plant Health Inspection Service at DigitalCommons@University of Nebraska - Lincoln. It has been accepted for inclusion in USDA National Wildlife Research Center - Staff Publications by an authorized administrator of DigitalCommons@University of Nebraska - Lincoln. 


\title{
Pheromonal control of the invasive brown treesnake: potency of female sexual attractiveness pheromone varies with ovarian state
}

\author{
Tom Mathies $^{\mathrm{a} *}$, Brenna Levine ${ }^{\mathrm{a}, \mathrm{b}}$, Richard Engeman ${ }^{\mathrm{a}}$ and Julie A. Savidge ${ }^{\mathrm{b}}$ \\ ${ }^{a}$ US Department of Agriculture, Animal Plant Health Inspection Service, Wildlife Services, National Wildlife Research Center, Fort \\ Collins, Colorado, USA; ${ }^{b}$ Department of Fish, Wildlife and Conservation Biology, Colorado State University, Fort Collins, Colorado, \\ USA
}

(Received 12 November 2012; final version received 7 March 2013)

\begin{abstract}
The female sex pheromone has potential a s a control tool for the Brown Treesnake, Boiga irregularis Merrem, a pest introduced into Guam. We conducted male-guided bioassays to determine whether potency of the female pheromone varied according to reproductive state and during vitellogenesis. In weekly simultaneous choice tests, we presented males with skin lipid samples from vitellogenic females, non-vitellogenic females, conspecific males, and carrier controls. The total time each sample was tongue-flicked was recorded: mean total tongue-flick time was highest for samples from vitellogenic females followed by samples from non-vitellogenic females. Pair-wise comparisons of male tongue-flick time for samples of non-vitellogenic females versus males and vitellogenic females versus non-vitellogenic females revealed differences in some weeks, but the greatest and most frequent differences were between vitellogenic females versus males. We observed no trend in the potency of the pheromone during vitellogenesis. Pheromone potency was greatest during vitellogenesis, with lesser potency retained while non-reproductive. Efforts at chemical identification of the pheromone and development of control tools should focus on material obtained from vitellogenic females.
\end{abstract}

Keywords: bioassay; biological control; chemical communication; invasive species; Reptilia; vitellogenesis

\section{Introduction}

Sex pheromones have been successfully used to control invasive species, particularly those depending on chemical communication of reproductive state to conspecifics to coordinate reproductive activities (Sorensen and Stacey 2004; Witzgall et al. 2010). Although this approach has had the greatest success on insects, its potential for use against invasive vertebrates that also depend on chemical messaging to communicate reproductive state is well recognized (Muller-Schwartz 1983; Corkum 2004; Wagner et al. 2006). Use of sex pheromones to help control invasive reptiles holds special promise because reptiles are among the most sensitive of all vertebrates to chemical cues in the environment (Schwenk 1995) and vomerolfaction is thought to be the dominant sensory mode governing many complex behaviours (Halpern 1992).

The number of invasive reptile species posing demonstrated adverse ecological and economic costs is increasing (Bomford et al. 2005; Kraus 2009). Foremost among these species is the Brown Treesnake (Boiga irregularis Merrem) on Guam. Methods for control of this tropical colubrid of Australasian origin have been thus far successful in confining it to Guam (Engeman and Vice 2001), although there is speculation that it has become established on nearby Saipan (Colvin et al. 2005). Regardless, additional tools are needed for further control (ideally, eradication), as the snake continues to inflict serious biological damage in the Pacific Islands Region (Engeman and Vice 2001; Colvin et al. 2005).

A nascent line of research at our facility at the National Wildlife Research Center is investigating the use of female sexual attractivity pheromone for potential inclusion in an integrated pest management strategy for the brown treesnake (see Colvin et al. 2005). Three applications under consideration are (i) as an "assay" for suspected incipient populations elsewhere in the Pacific Islands Region (e.g. standard United States Department of Agriculture brown treesnake traps baited with pheromone placed in areas of recent snake captures or sightings), (ii) local population suppression through "lure and kill" of sexually mature males, and (iii), if applied on a sufficiently wide scale, population suppression through disruption of the chemosensory abilities of males to locate and mate with females. All three approaches have been used successfully to control invasive insects (e.g. Cardé and Minks 1995; Suckling 2000; Myers and Hosking 2002; Gillette et al. 2006; Baker 2011).

The idea to development an effective and practical, pheromonally based tool for control of brown treesnakes is not a new (e.g. Mason 1999; Mason and Greene 2001). Realization of the concept is formidable, however, as no

\footnotetext{
*Corresponding author. Email: tomcmathies@gmail.com

(C) 2013 The work was authored as part of Tom Mathies, Brenna Levine, Richard Engeman and Julie A. Savidge's official duties as an employee of the United States Government and is therefore a work of the United States Government. In accordance with 17 U.S.C. 105 no copyright protection is available for such works under U.S. law
} 
pheromonally based tool has yet been developed for the control of any reptile. Nevertheless, studies on the pheromonal component of reproduction in snakes have a long history, beginning with the findings of Noble and Clausen (1936) that male Storeria dekayi Holbrook depend primarily on their olfactory senses to detect and locate females. Reproductive females of Thamnophis sirtalis L. and Thamnophis butleri Cope express the attractivity pheromone on their dorsal and lateral skin and males locate females by following non-volatile pheromone trails left by females on substrate (Noble 1937). In T. s. parietalis Say the pheromone is produced during ovarian recrudescence (Mendonça and Crews 1996) in the liver under control of oestrogen (Parker and Mason 2012), then transported in the circulatory system, and expressed on the skin (Garstka et al. 1981, 1982). Further studies on this species showed that the female attractivity pheromone is a component of the integumental skin lipids, and it comprises a non-volatile series of saturated and monounsaturated methyl ketones (Mason et al. 1989).

However, chemical characterization of pheromones can be difficult, and synthetic approximations may not be as effective as the natural compound (e.g. T. s. parietalis; Mason et al. 1990). Because our work is of applied nature, our initial goal necessitated determination of the phenology of sex pheromone expression in female B. irregularis: we asked whether potency of the female sex attractiveness varies with reproductive state (ovaries quiescent vs. recrudescent), and whether it varies during ovarian recrudescence. Several studies on snake sex pheromones investigated the former question by comparing chemical profiles of pheromone from different seasons (LeMaster and Mason 2001; Parker and Mason 2009), and the latter question using male behavioural assays (Shine et al. 2005; Uhrig et al. 2012) together with chemical profile comparisons (Uhrig et al. 2012), but only in T. s. parietalis (but see Aldridge et al. 2005: Nerodia). Decisions on whether to attempt to synthesize the pheromone, or "harvest" quantities from wild-caught females, depend on such information.

\section{Methods}

\subsection{Animals}

Adult, wild-caught $B$. irregularis were obtained from the United States Department of Agriculture (USDA), Wildlife Services (WS), Guam. Males $(n=49)$ and females $(n=17)$ were caged singly in separate climate-controlled animal rooms at the USDA, National Wildlife Research Center (NWRC), Fort Collins, Colorado, USA. Cages of males contained a $10-\mathrm{cm}$ inner diameter capped PVC refuge tube, which could be attached to a testing arena. Air temperature and relative humidity in all rooms containing snakes were maintained at about $28^{\circ} \mathrm{C}$ and $65 \%$, respectively. Each snake was fed one dead adult mouse (mean mass $=25 \mathrm{~g}$ ) once a week, and drinking water was provided ad libitum. Light cycles in both rooms were $12 \mathrm{~h}$ light : $12 \mathrm{~h}$ dark throughout all phases of this study.

\subsection{Release of vitellogenesis}

Boiga irregularis is an ideal model for investigating whether the female attractiveness pheromone varies with female reproductive state, because: (i) males are continuously reproductive (Mathies et al. 2010), (ii) females may be vitellogenic any month of the year on Guam (Savidge et al. 2007), (iii) mating is known to occur when females are vitellogenic (Mathies and Miller, 2003), and (iv) vitellogenesis can be experimentally elicited in the laboratory (Mathies and Miller 2003, 2004). Male-guided bioassays can therefore be conducted concurrently on both reproductive and non-reproductive females and at any time of year. In our study, vitellogenesis was elicited by exposing female $B$. irregularis to a period of relatively cool temperatures following methods modified from Mathies and Miller (2003, 2004). On 17 March 2008, nine of the 17 females were randomly selected and transferred in their cages to a room maintained at $20-21^{\circ} \mathrm{C}$. Between 8 and 20 May, 2008 room air temperatures were raised gradually back to $28^{\circ} \mathrm{C}$. The females were then returned to the room containing the other eight that had been maintained at $28^{\circ} \mathrm{C}$ throughout this period. The cooling period, including the period of transitional temperatures, was $52 \mathrm{~d}$. Feeding was then increased, offering all 17 females two adult mice a week. We began palpating ovaries of all 17 females for developing vitellogenic follicles $10 \mathrm{~d}$ prior to the end of the cool period. The person doing the palpation used both hands to hold a female on her back at about the position of the ovaries while a second person restrained her head. Vitellogenic follicles, when present, could be bracketed between the tips of thumbs. Once a randomly chosen follicle was thus bracketed, the second person measured its length with a ruler to the nearest millimetre. Because of the treesnake's slim body plan, even newly developing vitellogenic follicles could be measured fairly accurately (see Results). Each female was palpated once a week thereafter until follicular atresia began. Female $B$. irregularis do not ovulate unless they are mated; follicles, all of which attain preovulatory size, become atretic and are gradually resorbed (Mathies and Miller 2004). All preovulatory follicles within a female become atretic at the same time, as judged by their unmistakably flaccid feel, and the transition between viable and atretic apparently occurs quickly (between one week and the next). Flaccid follicles could not be accurately measured; that such flaccid-feeling follicles are atretic has been validated through dissections of fieldcollected vitellogenic females held in captivity (T. Mathies, unpublished data). Females that became vitellogenic and those that did not are referred to hereafter as "vitellogenic females" and "non-vitellogenic females", 
respectively. Some females initiated vitellogenesis before we were prepared to start the male behavioural trials. These females were not tested in the first 1-2 weeks of this experiment and sample sizes in those weeks are thus small.

All nine of the females exposed to cool temperatures developed vitellogenic follicles and were thus considered reproductive. None of the eight females maintained under the normal temperature regime developed vitellogenic follicles. The period over which females initiated vitellogenesis varied considerably among females; initial detections of enlarging follicles began with three females on 30 June 2008 and ended with one female on 11 August 2008. Thus, timing of the onset of vitellogenesis varied considerably among females despite exposure of snakes to identical environmental conditions. For the purposes of statistical analyses and graphical display, individual phenologies of vitellogenesis were normalized to a common start point, being the week when vitellogenic follicles were first detected in a female (hereafter 'Week 1', and so on for following weeks). All nine reproductive females maintained viable vitellogenic follicles up until at least Week 5. Atretic follicles were first detected in one female at Week 6 , in six more reproductive females by Week 7 , and by Week 8 only one reproductive female contained viable follicles. Thus, durations over which vitellogenic follicles remained viable also varied among individuals. For the purposes of characterizing growth of vitellogenic follicles we used observations on females with viable follicles up to Week 7. Responses of males to skin lipid samples of reproductive and non-reproductive females were examined during Weeks 1-6. Responses of males to skin lipid samples of reproductive females with atretic follicles and non-reproductive females were examined in Weeks 7-9.

\subsection{Skin lipid sample bioassays}

Each week, we conducted up to nine behavioural trials using skin lipid samples. We used opaque-sided Plexiglass arenas $(54 \mathrm{~cm}$ across front side, $25 \mathrm{~cm}$ across back side, $30.5 \mathrm{~cm}$ front to back, $14 \mathrm{~cm}$ deep, with clear Plexiglass lids) to test the behavioural responses of males to skin secretion samples of females, conspecific males, and carrier controls. Paper chip bedding was provided as substrate. Each arena had a port on its side to which a male within its hide tube could be attached. Samples to be evaluated by males were placed on the floor of each arena within eight, $6-\mathrm{cm}$ wide slots located along the opposite side of the arena from the male entry port. The narrowness of a slot allowed a male to easily tongue-flick the sample, but prevented him from crawling over it, thus obviating possible crosscontamination among samples. On the day a trial was conducted, a skin lipid sample was obtained from a vitellogenic female, a non-vitellogenic female, and a male. Nine males were used exclusively for the purpose of obtaining these samples. Samples were always collected from the same trio of individuals (vitellogenic female, non-vitellogenic female, and male) on each test date. Samples were obtained by swiping a $25-\mathrm{mm}$ diameter filter paper disk soaked with hexane/methylene chloride $(1: 1)$ three times down either the anterior or posterior dorsolateral side of a snake. We generally alternated sampling of the dorsolateral quadrants on an individual such that 3 weeks elapsed before the same quadrant was resampled. This rotation of sampling was conducted to allow regeneration of skin lipids and to avoid potential irritation to the integument (none observed). After evaporating the solvent, each sample-containing piece of filter paper was affixed flat on a $5-\mathrm{cm}^{2}$ piece of glazed ceramic tile with a strip of masking tape across an edge of the filter paper. Each trial consisted of a simultaneous choice test of six sample types: (i) skin lipids from a vitellogenic female, (ii) skin lipids from a non-vitellogenic female, (iii) skin lipids from a conspecific male, (iv) filter paper with solvent evaporated off and affixed to tile with tape, (v) filter paper without solvent and affixed to tile with tape, and (vi) ceramic tile with affixed tape. The four non-female derived samples served as controls. In total, 40 males were used in behavioural trials and were tested in random order. We continued to collect and test skin lipid samples from a reproductive female weekly for 3 weeks after follicular atresia was first detected in that female.

Behavioural trials were conducted in a separate dedicated animal room with environmental conditions as described above under Animals. An infrared camera (Weather-proof IR Colour Day/Night Camera, Model: PC177IR-4, Supercircuits, Inc., Austin, Texas, USA) was mounted above each test chamber and was attached to a mobile Video Cassette Recorder. Each trial was recorded on video tape (T-160 HQ VHS Video Tape, FUJIFILM USA Inc., Edison, New Jersey, USA). At the start of a trial the six test samples were placed one-to-a-slot in the innermost six test slots in random order. The outermost slots were not used because snakes often follow walls within a test apparatus (Ford 1986). A hide tube containing a male was then attached to the port of the arena, the video recorders switched on, and the room exited by the researcher for the duration of the trials. Trials were initiated in this manner approximately five hours before room lights were programmed to turn off. Males generally entered into a test arena and began investigating test samples soon after the room lights were shut off. The following morning, the male was returned to his home cage and the arena and ceramic tiles were washed thoroughly in a Steris Basil 4600 tunnel washer (Steris Corp., Beauport, Canada), before use in the next trial. Videotapes were reviewed using a Panasonic TV/DVD/VCR Combination (Model PV-DM2794, Panasonic Consumer Electronics Company, Secaucus, New Jersey, USA). For each trial we extracted the total time (seconds) that a male tongueflicked each of the six sample types. Data extractions were conducted single-blind. In each of the tongue-flicking 
events the male angled his head downwards within $1-2 \mathrm{~mm}$ of the filter paper (or place of the filter paper in the control sample without filter paper) and just the tip of the tongue was extended to contact the filter paper. For each trial, we only collected data for a male's first visit to each sample type. We used total tongue-flick time because we never observed certain courtship behaviours said to be stereotypical for male B. irregularis (i.e. "chin rubbing"; Greene et al. 2001), or found the behaviour (i.e. "head jerking"; Greene et al. 2001) to be directed at samples from both sexes (see Results).

\subsection{Statistical analyses}

Analyses were conducted using SAS software (Version 9.2, SAS Inc., Cary, North Carolina, USA). The individual growth model (Goldstein et al. 1994; McArdle and Bell 2000) was used to examine trajectories of follicular growth both within individual females and as a group. A balanced design was not required for this procedure. An unconditional linear model was fitted using PROC MIXED (Littell et al. 1996). The intercepts and slope were fitted as random effects that varied across individuals. The COVTEST option was included to test the variance and covariance components and a CLASS variable for individual females specified there were repeated measures on each female. Male response to test samples was examined using PROC GLM. The response variable was total tongue-flick time, the fixed effect was test sample type, and design was blocked by individual male because each male accessed each sample type each trial. Separate analyses were conducted by week because some males were tested twice ( $n=19$, none same week). The following comparisons were made by week using a priori contrasts: males versus non-vitellogenic females, males vsersus vitellogenic females, and non-vitellogenic females vsersus vitellogenic females. Means \pm 1 standard error are presented.

\section{Results}

\subsection{Precision of detection of vitellogenesis and rate of follicular growth}

The unconditional linear growth model for follicular growth yielded an estimated variance of intercepts and slopes of $0.22 \pm 0.26(P=0.19)$ and $0.003 \pm 0.01(P=$ $0.39)$, respectively (Figure 1B). Thus, neither intercepts
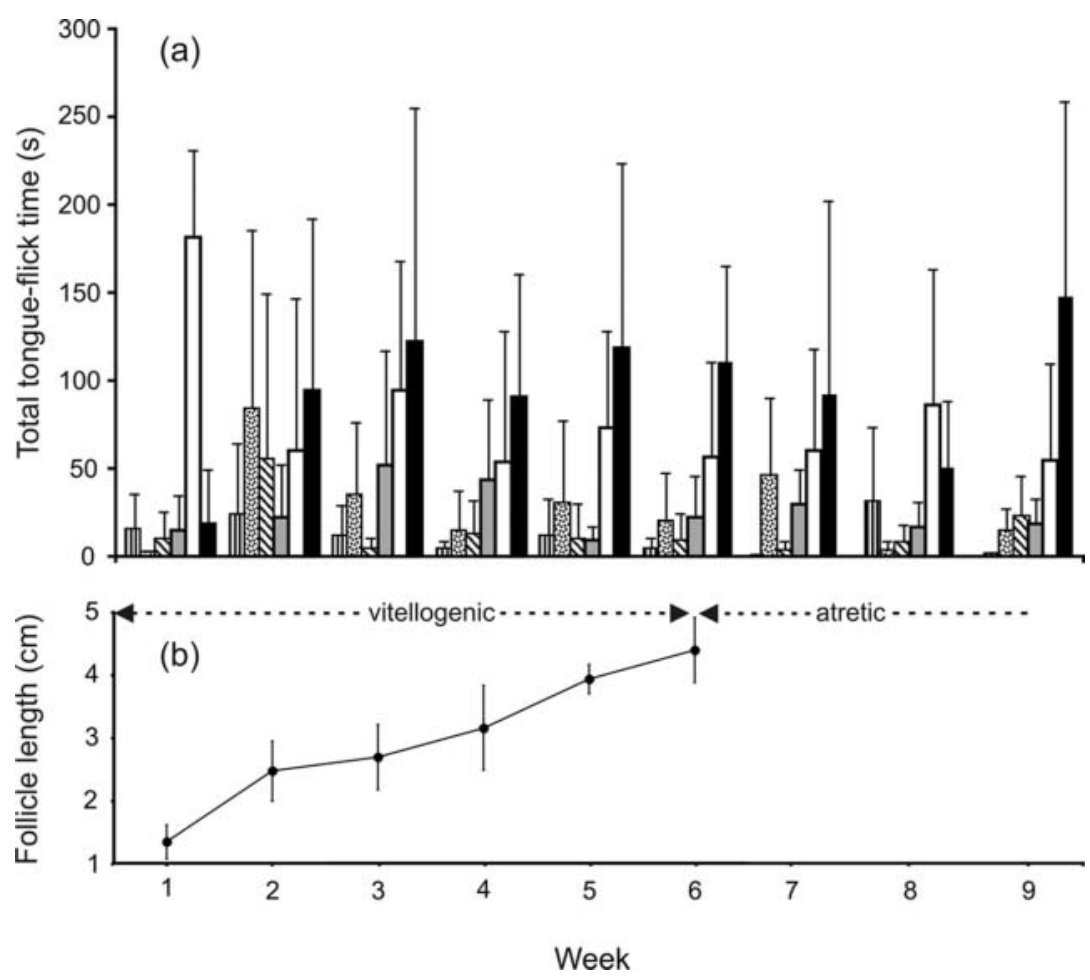

Figure 1. (a) Mean ( $\pm 1 \mathrm{SD})$ total tongue-flick time of male brown treesnakes (Boiga irregularis) toward filter paper containing skin lipid samples or carrier controls. $\square=$ females with vitellogenic follicles (Weeks 1-6) or atretic follicles (Weeks 7-9); $\square=$ females with non-vitellogenic follicles; $\square=$ conspecific males. Carrier controls: $\mathbf{Q}=$ solvent-soaked filter paper (evaporated) affixed to tile; G = filter paper affixed to tile; 西 = ceramic tile base. There were differences in mean tongue-flick time among treatments in 7 of 9 weeks and in some pair-wise comparisons in all weeks (see Table 1). (b) Mean ( \pm 1 SD) vitellogenic follicle length of females used to obtain skin lipid samples subjected to male bioassays. Ovarian follicles within vitellogenic females were viable weeks 1-6, but were undergoing atresia and could not be measured weeks 7-9 (see Methods and Results). 
nor slopes for follicular growth varied among females. The absence of differences in intercepts among individuals indicates that the size at which vitellogenic follicles were first detected did not differ among females and that our methods for detection were therefore sufficiently precise. Lack of differences in slopes indicates that rates of vitellogenesis were similar among females. The average length of vitellogenic follicles at first detection (y-intercept at Week 1) was $1.09 \pm 0.24 \mathrm{~cm}(P=0.002)$ and the average increase in follicle length was $0.54 \pm 0.05 \mathrm{~cm}$ per week $(P<0.0001)$. A quadratic model fitted to the data did not give an improved fit.

\subsection{Skin lipid sample bioassays}

Mean total tongue-flick time varied among sample types in Weeks 3-9 (Table 1) and was highest for samples from vitellogenic females in five of six weeks during the period of vitellogenesis and two of three weeks during the period of atresia (Figure 1A). Mean tongue-flick time for samples from non-reproductive females was higher than controls (those from males included) in eight of the nine weeks' study period. Results for a priori contrasts (Table 1) indicated that differences observed in the overall tests were due primarily to differences between male response to samples from reproductive females (vitellogenic and atretic) versus samples from males, where only in Weeks 1 and 8 were differences not indicated (Table 1). In contrast, differences in male response to samples from non-reproductive females versus males were not indicated in Weeks 2, 3, 4 and Weeks 7, 8, 9 (Table 1). Differences in male response to samples from reproductive females versus nonreproductive females were observed only in Weeks 1, 5, 6 while follicles were viable and Week 9 by which time follicles had become atretic and were quite flaccid (Table 1).

In Weeks 3-6, the period during vitellogenesis when sample sizes were largest, there was no apparent trend in potency of the pheromone; mean male tongue-flick time was similar among these weeks and remained high even in Weeks 7-9 when all reproductive females contained atretic follicles.

The only putative male sexual behaviour toward the skin lipid samples we observed, other than the focused tongue-flicking described above, was "head jerking" behaviour as described by Greene et al. (2001). However, in our study this behaviour was not directed exclusively at samples from females; excepting samples from conspecific males, frequencies observed for samples from reproductive females $(n=7)$, non-reproductive females $(n=11)$, males $(n=4)$, and even carrier controls $(n$ values $=11,8,7)$ were similar.

\section{Discussion}

The results of the male bioassays of skin lipid samples demonstrate that the female sexual attractiveness pheromone in brown treesnakes is produced mainly while the ovaries are undergoing vitellogenesis. An unexpected and novel finding was that a less potent form (or concentration) of the pheromone is present while the ovaries are reproductively quiescent. It is unknown whether females of temperate zone snakes express the sexual attractiveness pheromone outside of the mating season or whether this condition is restricted to tropical species like $B$. irregularis where reproduction in both sexes may occur throughout the year (see Savidge et al. 2007; Mathies et al. 2010). Conducting such tests on temperate zone species can be inherently difficult because, in many species, the period when males exhibit courtship behaviour is limited to the period when females are undergoing, or are about to undergo (i.e. Thamnophis spp.), ovarian growth (Aldridge and Duvall 2002; Aldridge et al. 2009); males are not sexually active while females are reproductively quiescent and therefore cannot be used in bioassays. Variation in sexual attractiveness pheromone and male response to the pheromone has been demonstrated in female $T$. s. parietalis, where a greater proportion of males

Table 1. Results of generalized linear mixed model type III tests and a priori contrasts for effects of skin lipid sample type and carrier controls on total tongue-flick duration time by male brown treesnakes, Boiga irregularis. ${ }^{\text {a }}$

\begin{tabular}{|c|c|c|c|c|c|}
\hline \multirow[b]{2}{*}{ Week } & \multirow[b]{2}{*}{$n$} & \multirow[b]{2}{*}{ Treatment } & \multicolumn{3}{|c|}{ A priori contrasts } \\
\hline & & & NVF vs. M & VF vs. M & VF vs. NVF \\
\hline 1 & 3 & $F_{5,10}=1.6, P=0.25$ & $F_{2,3}=4.6, P=0.06$ & $F_{2,3}<0.1, P=0.96$ & $F_{2,3}=4.4, P=0.06$ \\
\hline 2 & 4 & $F_{5,15}=2.0, P=0.14$ & $F_{2,4}=1.6, P=0.22$ & $F_{2,4}=5.8, P=0.03$ & $F_{2,4}=1.3, P=0.27$ \\
\hline 3 & 7 & $F_{5,30}=3.2, P=0.02$ & $F_{2,7}=1.4, P=0.25$ & $F_{2,7}=3.7, P=0.06$ & $F_{2,7}=0.6, P=0.46$ \\
\hline 4 & 7 & $F_{5,29}=3.1, P=0.02$ & $F_{2,7}=0.2, P=0.66$ & $F_{2,7}=3.0, P=0.09$ & $F_{2,7}=1.7, P=0.20$ \\
\hline 5 & 9 & $F_{5,39}=5.9, P=0.0004$ & $F_{2,9}=5.0, P=0.03$ & $F_{2,9}=15.9, P=0.0003$ & $F_{2,9}=3.2, P=0.08$ \\
\hline 6 & 7 & $F_{5,30}=8.9, P=0.0001$ & $F_{2,7}=3.1, P=0.09$ & $F_{2,7}=21.2, P=0.0001$ & $F_{2,7}=8.1, P=0.008$ \\
\hline 7 & 6 & $F_{5,25}=2.4, P=0.06$ & $F_{2,6}=0.9, P=0.34$ & $F_{2,6}=3.9, P=0.06$ & $F_{2,6}=1.6, P=0.33$ \\
\hline 8 & 6 & $F_{5,25}=3.2, P=0.01$ & $F_{2,6}=8.8, P=0.007$ & $F_{2,6}=2.0, P=0.16$ & $F_{2,6}=2.3, P=0.14$ \\
\hline 9 & 5 & $F_{5,20}=5.6, P=0.002$ & $F_{2,5}=1.2, P=0.29$ & $F_{2,5}=15.9, P=0.0007$ & $F_{2,5}=8.4, P=0.009$ \\
\hline
\end{tabular}

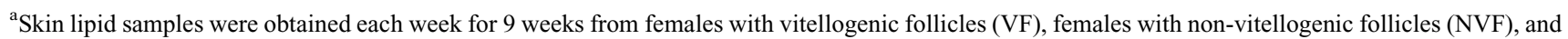
males (M); females contained enlarging follicles weeks 1-6 and atretic follicles weeks 7-9. 
displayed courtship behaviours toward skin lipid samples from large females that had pheromone profiles dominated by unsaturated methyl ketones versus small females that had profiles dominated by saturated methyl ketones (LeMaster and Mason 2002; see also Shine et al. 2003). Why female brown treesnakes continue to express a relatively low potency form or concentration of sexual attractiveness pheromone outside the period of vitellogenesis is unknown; it is unlikely that mating occurs outside this period as sperm has not been found within oviducts of nonvitellogenic females, and oviductal sperm storage structures were reported to be absent in this species (Bull et al. 1997).

We found no support for the idea that pheromone potency varies during vitellogenesis - recognizing, however, that sample sizes in Weeks 1-3 were too small to detect such variation. In addition, although vitellogenesis in each female had been in progress for an undetermined time prior to its first detection, the duration was likely brief; vitellogenesis in brown treesnakes is initiated in hydration stage follicles averaging $5 \mathrm{~mm}$ in length (Savidge et al. 2007), follicle length at first detection was about $1 \mathrm{~cm}$, and the rate of increase in follicle length was $0.54 \mathrm{~cm}$ a week, as determined herein. Thus, vitellogenesis in each of our females was initiated only about one week before it was first detected. In contrast to our findings, the few other studies to investigate variation in pheromone potency during vitellogenesis found that pheromone potency declined during vitellogenesis (T. s. parietalis: Shine et al. 2005; Uhrig et al 2012), or inferred that either pheromone potency or release were intermittent during vitellogenesis (Nerodia sipedon Linnaeus: Aldridge et al. (2005). Studies on additional species are obviously needed, with special attention to female reproductive state, to determine whether there is a general phenology of female sex attractiveness pheromone expression in snakes.

It is unknown whether our finding that attractivity was maintained well into the period when vitellogenic follicles became atretic is an anomaly associated with what is presumably a rare event in the field: atresia of all ovulationready follicles as a result of failure to mate. That is, in vitellogenic females that are mated, it is possible that they become unattractive to males at that point. In recentlymated female $T$. sirtalis, a copulatory pheromone in association with a copulatory plug temporarily reduces attractivity in vitellogenic females (O'Donnell et al. 2004). On the other hand, newly gravid females may normally retain the level of attractiveness we observed here, but with another mechanism rendering females unattractive; Greene and Mason (2000) found that female brown treesnakes release cloacal secretions containing a pheromone that inhibits unwanted courtship and attempted matings from males. This pheromone may serve to obviate the effects of a "residual" female attractiveness pheromone.

Since publication of the two reviews presenting the case for pheromonal control of brown treesnake populations (Mason 1999; Mason and Greene 2001), knowledge has accumulated that limits the feasibility and scope of this approach. First, there is no evidence that brown treesnakes have a breeding season on Guam; females with enlarging vitellogenic follicles are found with similar frequencies in all months of the year (Savidge et al. 2007), and upon reaching adulthood, males have testes that remain fully recrudescent apparently for life (Mathies et al. 2010). Achieving population suppression using lure and kill of males or mating disruption approaches (widespread application of synthetic pheromone to the environment disrupting the ability or disposition of males to follow real pheromone trails laid down by receptive females) would therefore require field application of synthetic pheromone throughout the year and probably incur a prohibitive cost. Second, any pheromonallybased approach would have to outperform current technologies for population suppression of the brown treesnake, namely, live trapping using a live mouse bait (Engeman et al. 1998; Engeman and Vice 2001) and particularly, ground or aerially delivered dead mouse baits laced with toxicants (Savarie et al. 2001). Both technologies are superior to a female sex pheromone attractant because both use a bait that emits a volatile odour plume that both sexes, of all but the youngest age classes, follow to the source (Shivik 1998; Jojola-Elverum et al. 2001), and both result in immediate elimination of individuals from the population. In contrast, the female sex pheromone in reptiles is thought to be a non-volatile substrate contact chemical (Mason 1992; but see also Aldridge et al. 2005) of interest primarily to adult males. Field application would be labour-intensive if using artificial trails in a lure-and-kill approach, and slow and costly to effect a population reduction if using aerial broadcast in a mating disruption approach.

We believe that the most useful role for a pheromonal tool within the integrated pest management strategy for the brown treesnake is as an assay for suspected incipient populations on other islands at risk in the Pacific region. These are all areas with high prey diversity and availability, where a sex pheromone might be expected to outperform a food-based attractant. In support of this contention, work on Guam has shown that brown treesnakes were less trappable on unmanipulated plots than plots where prey densities were experimentally reduced below normal (Gragg et al. 2007). Such a pheromonal detection tool has practicality, in part, because large quantities of pheromone would not be required. A primary reason we investigated the possibility that nonvitellogenic females might also express the sexual attractivity pheromone is that large numbers of adult females are collected each year by USDA WS's operational snake control programme and quantities of pheromone-containing skin secretions could therefore be harvested and stored until use. However, our finding that the more potent form 
or concentration of this pheromone is produced by vitellogenic females may make this approach less desirable. Vitellogenic females are comparatively difficult to obtain, in part because few can be collected at any one time of year. For example, during a 30-d period (14 April-20 May 2009), one of us (T.M.) examined all snakes collected by the WS from the over 3000 traps held in constant operation. Of the 319 snakes captured during that period, 51 were sexually mature females of which only nine $(18 \%)$ contained large vitellogenic follicles. A rough estimate, then, of the number of vitellogenic females that could be obtained making use of operationally collected snakes is 70 per year. It is unknown whether quantities of pheromone collected from this number of females would meet the needs for a pheromonally based detection tool. Such need would depend on a number of factors, as yet unknown, including storage stability of the pheromone and its field life following deployment. It is certain, however, that any other use (e.g. mating disruption) will require much larger quantities of pheromone and thus synthesis of a chemical approximation. The chemical identity of the sexual attractiveness pheromone in female brown treesnakes, despite attempts at its identification, remains unknown. Use of the same experimental paradigm used to identify the pheromone in a garter snake (i.e. Mason et al. 1989), yielded a novel series of methyl ketodienes (in addition to series of long-chain saturated and monounsaturated methyl ketones similar to those comprising the sex pheromone in garter snakes) in the skin lipids of female brown treesnakes (Murata et al. 1991). However, it was reported that male bioassays of these constituents were "ambiguous" (Mason 1999) and eluted fractions of female skin lipids eliciting the highest levels of male courtship behaviour were said not to contain methyl ketones (Greene and Mason 1998). Renewed work on identification of the pheromone is thus needed if yields from operationally-collected snakes do not meet control needs.

We still lack the most critical piece of information needed to evaluate the feasibility of a pheromonal control tool: the propensity and tenacity of males to follow pheromone trails. Most studies on sex pheromone-mediated trailing behaviour in snakes have been conducted on one genus, Thamnophis (Ford 1982; Ford and Lowe 1984; LeMaster and Mason 2001; LeMaster et al. 2001; O’Donnell et al. 2004, but see Andrén 1986: Vipera berus Linnaeus; Lillywhite 1985: Coluber constrictor AUITH Say; Plummer and Mills 1996: Heterodon platyrhinos Latreille, in Sonnini and Latreille; Fornasiero et al. 2007: Hierophis viridiflavus Lacépède). In all these studies the experimental trailing distances allowed were likely short compared to those laid down by females in the natural environment (i.e. non-denning species that mate upon spring emergence). To be efficacious and cost effective, male brown treesnakes would have to exhibit good propensity to follow reasonably long trails (i.e. $>50 \mathrm{~m}$ ). Experiments have been conducted on trailing behaviour of male brown treesnakes using a short Y-maze (maze arms $\sim$ $2 \mathrm{~m}$ long - the mean minimum size of male brown treesnakes at sexual maturity is approximately $1 \mathrm{~m}$ snoutvent length; Savidge et al. 2007). But those results were equivocal: adult males trailed adult conspecifics, but showed no preference for females said to be "in breeding condition" over males (Greene et al. 2001). Thus, it remains to be determined whether males will reliably trail vitellogenic females over laboratory-scale distances, much less the considerably longer distances in the field required to make a pheromonal control tool practical. Further, although it has been demonstrated that the female sexual attractiveness pheromone is the same pheromone mediating reproductive trailing behaviour in at least one snake species (T. s. parietalis (LeMaster and Mason 2001), we feel it is premature to assume this parity in the brown treesnake.

Determinations of whether male brown treesnakes follow pheromone trails of females should first be conducted using relatively short pheromone trails in a laboratory setting before attempting the considerably more difficult task of assessing distances males will trail females in the field. The length of time sex pheromone trails persist in the environment has not been investigated, but in trials conducted using African brown house snakes (Boaedon fuliginosus Boie) in an indoor Y-maze, all 14 males were able to effectively follow trails of females for up to seven days post-trail establishment, with the percentage of males effectively trailing declining to $74 \%$ seven days later (Wilmes et al. 2012). Ultimately, use of a pheromone attractant as an assay for incipient populations will need to show superiority in the field in head-to-head comparisons with a food-based attractant (Savarie et al. 2001) and nocturnal visual surveys (Christy et al. 2010) before further development is considered.

\section{Declaration}

All work was conducted under the research protocol QA-1438 reviewed and approved by the NWRC Institutional Animal Care and Use Committee and conformed to the applicable federal and state legal requirements, including those related to conservation and welfare of animals. All aspects of this study were conducted in accordance with the Helsinki Declaration. Snakes were maintained at NWRC under US Fish and Wildlife Service Injurious Wildlife Permit No. MA097832-0 to R. Bruggers.

\section{Disclaimer}

Use of a trade name does not constitute endorsement by the USA government. 


\section{Acknowledgements}

We thank D. Vice at USDA Wildlife Services, Guam for providing snakes used in this study and A. Vigil at Delta Air Lines, Guam for the considerable effort needed to arrange their air transport. We also thank the Animal Care Staff at the NWRC for their efforts in accommodating and caring for these animals.

\section{References}

Aldridge RD, Bufalino AP, Reeves A. 2005. Pheromone communication in the watersnake, Nerodia sipedon: A mechanistic difference between semi-aquatic and terrestrial species. Am Midl Nat. 154:412-422.

Aldridge RD, Duvall D. 2002. Evolution of the mating season in the pitvipers of North America. Herpetol Monogr. 16:1-25.

Aldridge RD, Goldberg SR, Wisniewski SS, Bufalino AP, Dillman CB. 2009. The reproductive cycle and estrus in the colubrid snakes of temperate North America. Contemp Herpetol. 4:1-31.

Andrén KP. 1986. Courtship, mating and agonistic behaviour in a free-living population of adders, Vipera berus (L.). Amphibia-Reptilia. 7:353-383.

Bomford M, Kraus J, Braysher M, Walter L, Brown L. 2005. Risk assessment model for the import and keeping of exotic reptiles and amphibians. Report to Bureau of Rural Sciences, Canberra, Australia. p. 110.

Baker TC. 2011. Insect pheromones: useful lessons for crustacean pheromone programs? In: Breithaupt T, Thiel M, editors. Chemical communication in crustaceans. New York: Springer. p. 531-550.

Bull KH, Mason RT, Whittier J. 1997. Seasonal testicular development and sperm storage in tropical and subtropical populations of the brown tree snake (Boiga irregularis). Aust $\mathrm{J}$ Zool. 45:479-488.

Cardé RT, Minks AK. 1995. Control of moth pests by mating disruption: successes and constraints. Annu Rev of Entomol. 40:559-585.

Colvin BA, Fall MW, Fitzgerald LA, Loope LL. 2005. Review of brown treesnake problems and control programs: Report of observations and recommendations. Report to Department of Interior, Office of Insular Affairs, Honolulu, Hawai'i. Available at: http://www.fort.usgs.gov/resources/ education/bts/resources/pdf/Colvin2005BrownTreesnake ReviewPanelReport.pdf (accessed 21 February 2013).

Corkum LD. 2004. Pheromone signaling in conservation. Aquat Conserv. 14:327-331.

Christy MT, Adams AA, Rodda GH, Savidge JA, Tyrrell CL. 2010. Modelling detection probabilities to evaluate management and control tools for an invasive species. J Appl Ecol. 47:106-113.

Engeman RM, Linnell MA, Pochop PA, Gamboa J. 1998. Substantial reductions of brown tree (Boiga irregularis) populations in blocks of land on Guam through operational trapping. Int Biodeterior. 42:167-171.

Engeman RM, Vice DS. 2001. Objectives and integrated approaches for the control of brown treesnakes. Integ Pest Manage Rev. 6:59-76.

Ford NB. 1982. Species specificity of sex pheromone trails of sympatric and allopatric garter snakes (Thamnophis). Copeia. 1982:10-13.

Ford NB. 1986. The role of pheromone trails in the sociobiology of snakes. In: Duvall D, Müller-Schwarze D, Silverstein $\mathrm{RM}$, editors. Chemical signals in vertebrates 4: ecology, evolution and comparative biology. New York: Plenum Press. p. 261-278.

Ford NB, Low JR. 1984. Sex pheromone source location by garter snakes: a mechanism for detection of direction in nonvolatile trails. J Chem Ecol. 10:1193-1199.

Fornasiero S, Bresciani E, Dendi F, Zuffi MAL. 2007. Pheromone trailing in male European whip snake, Hierophis viridiflavus. Amphibia-Reptilia. 28:555-559.

Garstka WR, Camazine B, Crews D. 1982. Interactions of behavior and physiology during the annual reproductive cycle of the red-sided garter snake (Thamnophis sirtalis parietalis). Herpetologica. 38:104-123.

Garstka WR, Crews D. 1981. Female sex pheromone in the skin and circulation of a garter snake. Science (NY). 214:681-683.

Gillette NE, Stein JD, Owen DR, Webster JN, Mori SR. 2006. Pheromone-base disruption of Eucosma sonomana and Rhyacionia bushnelli (Lepidoptera: Tortricidae) using aerially applied microencapsulated pheromone. Can J For Res. 36:361-368.

Goldstein H, Healy MJR, Rasbash J. 1994. Multilevel time series models with applications to repeated measures data. Stat Med. 13:1643-1655.

Gragg JE, Rodda GH, Savidge JA, White GC, Dean-Bradley K, Ellingson AR. 2007. Response of brown treesnakes to reduction of their rodent prey. J Wildl Manage. 71:2311-2317.

Greene MJ, Mason RT. 1998. Chemically mediated behavior of the brown treesnake, Boiga irregularis. Ecoscience. 5:405-409.

Greene MJ, Mason RT. 2000. The courtship, mating, and combat behavior of the brown tree snake, Boiga irregularis. Herpetologica. 56:166-175.

Greene MJ, Stark SL, Mason RT. 2001. Pheromone trailing behavior of the brown treesnake, Boiga irregularis. J Chem Ecol. 27:2193-2201

Halpern M. 1992. Nasal chemical senses in reptiles: structure and function. In: Gans C, Crews D, editors. Biology of the Reptilia 18. Chicago (IL): University of Chicago Press. p. 424-498.

Jojola-Elverum SM, Shivik JA, Clark L. 2001. Importance of bacterial decomposition and carrion substrate to foraging brown treesnakes. J Chem Ecol. 27:1315-1331.

Kraus F. 2009. Alien reptiles and amphibians: a scientific compendium and analysis. Dordrecht (Netherlands): Springer Science and Business Media.

LeMaster MP, Mason RT. 2001. Evidence for a sex pheromone mediating male trailing behavior in the red-sided garter snake, Thamnophis sirtalis parietalis. Chemoecology. 11:149-152.

LeMaster MP, Mason RT. 2002. Variation in female sexual attractiveness pheromone controls male mate choice in garter snakes. J Chem Ecol. 28:1269-1285.

LeMaster MP, Moore IT, Mason, RT. 2001. Conspecific trailing behavior of red-sided garter snakes, Thamnophis sirtalis parietalis, in the natural environment. Anim Behav. 61:827833.

Lillywhite HB. 1985. Trailing movements and sexual behavior in Coluber constrictor. J Herpetol. 19:306-308.

Littell RC, Milliken GA, Stroup WW, Wolfinger RD. 1996. SAS system for mixed models. Cary (NC): SAS Institute.

Mason RT. 1992. Reptilian pheromones. In: Gans C, Crews D, editors. Biology of the Reptilia 18 E. Hormones, brain and behavior. Chicago (IL): University of Chicago. p. 114-228.

Mason RT. 1999. Integrated pest management: The case for pheromonal control of Habu (Trimeresurus flavovirdis) and Brown treesnakes (Boiga irregularis). In: Rodda GH, Sawai Y, Chiszar D, Tanaka H, editors. Problem Snake 
Management: the Habu and the Brown Treesnake. Ithaca (NY): Cornell University Press. p. 196-205

Mason RT, Fales HM, Jones TH, Pannell LK, Chinn JW, Jr., Crews D. 1989. Sex pheromones in garter snakes. Science (NY). 245:290-293.

Mason RT, Greene MJ. 2001. Invading pest species and threat to biodiversity: Pheromonal control of Guam brown treesnakes, Boiga irregularis. In: A. Marchlewska-Koj A, Lepri JJ, Müller-Schwarze D, editors. Chemical signals in vertebrates 9. New York: Kluwer Academic/Plenum Publishers. p. 361-368.

Mason RT, Jones TH, Fales HM, Pannell LK, Crews D. 1990. Characterization, synthesis, and behavioral responses to sex attractiveness pheromones of red-sided garter snakes (Thamnophis sirtalis parietalis). J Chem Ecol. 16:2353-2369.

Mathies T. 2010. Reproductive cycles of tropical snakes. In: Aldridge RD, Sever DM, editors (Jamieson BGM, series editor). Reproductive biology and phylogeny of snakes 9, Reproductive Biology and Phylogeny series. Boca Raton (FL): CRC Press. p. 511-550.

Mathies T, Cruz JA, Lance VA, Savidge JA. 2010. Reproductive biology of male brown treesnakes (Boiga irregularis) on Guam. J Herpetol. 44:209-221.

Mathies T, Miller LA. 2003. Cool temperatures elicit reproduction in a biologically invasive predator, the brown treesnake (Boiga irregularis). Zoo Biol. 22:227-238.

Mathies T, Miller LA. 2004. Proximate cues for ovarian recrudescence and ovulation in the brown treesnake (Boiga irregularis) under laboratory conditions. Herpetol Rev. $35: 46-49$

McArdle JJ., Bell RQ. 2000. An introduction to latent growth models for developmental data analysis. In: Little TD, Schnabel KU, Baumert J, editors. Modeling longitudinal and multilevel data: practical issues, applied approaches, and specific examples. Mahwah (NJ): Lawrence Erbaum. p. 69-107.

Mendonça MT, Crews D. 1996. Effects of ovariectomy and estrogen replacement on attractivity and receptivity in the redsided garter snake (Thamnophis sirtalis parietalis). J Comp Physiol A. 178:373-381.

Muller-Schwartz D. 1983. Experimental modulation of behavior of free-ranging mammals by semiochemicals. In: Muller-Schwartz D, Silverstein RM, editors. Chemical signals in vertebrates III. New York (NY): Plenum Press. p. $235-244$.

Murata Y, Yeh HJC, Pannell LK, Jones TH, Fales HM, Mason RT. 1991. New ketodienes from the integumental lipids of the Guam brown tree snake, Boiga irregularis. J Nat Prod. 54:233-240.

Myers JH, Hosking G. 2002. Eradication. In: Hallman GJ, Schwalbe CP, editors. Invasive arthropods in agriculture: problems and solutions. Enfield (NH): Science Publishers. p. 293-307.

Noble GK. 1937. The sense organs involved in the courtship of Storeria, Thamnophis, and other snakes. B Am Mus Nat Hist. 73:673-725.
Noble GK, Clausen HJ. 1936. The aggregation behavior of Storeria dekayi and other snakes, with special reference to the sense organs involved. Ecol Monogr. 6:271-316.

O'Donnell RP, Ford NB, Shine R, Mason RT. 2004. Male redsided garter snakes, Thamnophis sirtalis parietalis, determine female mating status from pheromone trails. Anim Behav. 68:677-683.

Parker MR, Mason RT. 2009. Low temperature dormancy affects the quantity and quality of the female sexual attractiveness pheromone in red-sided garter snakes. J Chem Ecol. 35:1234-1241.

Parker MR, Mason RT. 2012. How to make a sexy snake: estrogen activation of female sex pheromone in male red-sided garter snakes. J Exp Biol. 215:723-730.

Plummer MV, Mills NE. 1996. Observations on trailing and mating behaviors in hognose snakes (Heterodon platyrhinos) J Herpetol. 30:80-82.

Savarie PJ, Shivik JA, White GC, Hurley JC, Clark L. 2001. Use of acetaminophen for large-scale control of brown treesnakes. J Wildl Manage. 65:356-365.

Savidge JA, Qualls FJ, Rodda GH. 2007. Reproductive biology of the brown tree snake, Boiga irregularis (Reptilia: Colubridae), during colonization of Guam and comparison with that in their native range. Paci Sci. 2:187-195.

Schwenk K. 1995. Of tongues and noses: chemoreception in lizards and snakes. Trends Ecol and Evol (Amst.). 10:7-12.

Shine R, Phillips B, Waye H, LeMaster M, Mason RT. 2003. Chemosensory cues allow courting male garter snakes to assess body length and body condition of potential mates. Behav Ecol Sociobiol. 54:162-166.

Shine R, Wall M, Langkilde T, Mason, RT. 2005. Battle of the sexes: forcibly inseminating male garter snakes target courtship to more vulnerable females. Anim Behav. 5: $1133-1140$

Shivik JA. 1998. Brown tree snake response to visual and olfactory cues. J Wildl Manage. 62:105-111.

Sorensen PW, Stacey NE. 2004. Brief review of fish pheromones and discussion of their possible uses in the control of non-indigenous teleost fishes. NZ J Mar Fresh. 38:399-417.

Suckling DM. 2000. Issues affecting the use of pheromones and other semiochemicals in orchards. Crop Prot. 19:677-683.

Uhrig EJ, Lutterschmidt DI, Mason RT, LeMaster MP. 2012. Pheromonal mediation of intraseasonal declines in the attractivity of female red-sided garter snakes, Thamnophis sirtalis parietalis. J Chem Ecol. 38:71-80.

Wagner CM, Jones ML, Twohey MB, Sorensen PW. 2006. A field test verifies that pheromones can be useful for sea lamprey (Petromyzon marinus) control in the Great Lakes. Can J Fish Aquat Sci 63:475-479.

Wilmes AJ, Rheubert JL, Gruenewald DL, Kotaru T, Aldridge RD. 2012. Conspecific pheromone trailing and pheromone trail longevity in the African colubrid Boaedon fuliginosus. Afr J Herpetol. 61:159-168.

Witzgall P, Kirsch P, Cork A. 2010. Sex pheromones and their impact on pest management. J Chem Ecol. 36:80-100. 